\title{
A DIÁSPORA LUSITANA CONTEMPORÂNEA. ASSOCIAÇÕES E OUTRAS REDES SOCIAIS NA EMIGRAÇÃO PORTUGUESA
}

\author{
Contemporary Portuguese diasporas. \\ Associations and other social networks in Portuguese migration
}

José Carlos Marques*
Pedro Góis**

\begin{abstract}
Resumo. O interesse global nas práticas de engajamento dos emigrantes em diáspora tem crescido um pouco por todo o mundo. São disso exemplo as políticas ligadas ao retorno de emigrantes qualificados, à promoção de brain gain, ou destinadas a estimular a formação de redes de diáspora. Através de políticas públicas e de uma estratégia de comunicação eficaz poderia ser possível, pelo menos do ponto de vista do país de origem, reverter o sentimento de perda sociológica que representa a emigração de uma parte da sociedade nacional. Baseado num mapeamento global do movimento associativo português, o artigo encontra-se estruturado em duas partes. Na primeira parte, discutem-se as perspetivas teóricas que têm analisado as políticas e as práticas de vinculação dos migrantes aos seus países de origem. Na segunda, partindo da análise da recente emigração portuguesa, analisamse, através de uma proposta de tipologia, as atuais formas organizativas dos portugueses no exterior.
\end{abstract}

Palavras-chave: diáspora portuguesa; associações; práticas de engajamento; migração portuguesa.

\begin{abstract}
The global interest in diaspora engagement has been growing all over the world. Examples of this are policies linked to the return of qualified emigrants, to the promotion of brain gain or aimed at stimulating the formation of diaspora networks. Through public policies and an effective communication strategy it might be possible, at least from the point of view of the country of origin, to reverse the feeling of sociological loss that the expatriation of part of the national society represents. Based on a global mapping of the Portuguese associative movement, the article is structured in two parts. In the first part, we discuss the theoretical perspectives which have analysed the policies and practices of migrants' attachment to their countries of origin. In the second,
\end{abstract}

* Centro Interdisciplinar de Ciências Sociais (CICS.NOVA.IPLeiria), Politécnico de Leiria. Leiria, Portugal. E-mail: jclaranjo@gmail.com. Orcid: https://orcid.org/0000-0002-4690-5943.

** Universidade de Coimbra, Faculdade de Economia e Centro de Estudos Sociais. Coimbra, Portugal. E-mail: pedro.gois@uc.pt. Orcid: https://orcid.org/0000-0002-5217-0285. 
starting from the analysis of recent Portuguese emigration, we analyse, through a proposal of a typology, the current organisational forms of the Portuguese abroad.

Keywords: portuguese diaspora; associations; engagement practices; Portuguese migration.

\section{Introdução}

O reconhecimento do potencial produtivo que ocorre nas diásporas tem sido assumido como positivo em várias esferas da sociedade de origem (Mahroum et al., 2006). Os governos têm olhado para as comunidades emigradas enquanto recurso multidimensional (remessas, capital humano, base eleitoral, base linguística, etc.), mas os municípios, as associações profissionais e empresariais, os sindicatos ou as empresas, também têm visto este recurso como parte dos seus próprios objetivos correntes ou de estratégias futuras (exportação de produtos e serviços ou acesso a novos mercados). Pressionados pela necessidade de uma maior competitividade internacional e pela existência de uma nova era de comunicação e informação, sobretudo a partir dos anos 90, os Estados e outros stakeholders têm sentido necessidade de lidar, por um lado, com novas questões face aos desafios da globalização e da livre circulação de ideias, serviços, capitais e produtos, e, por outro lado, com o aumento da intensidade do transnacionalismo e da circulação de trabalhadores, quadros técnicos e suas famílias (Song, 2014).

Neste contexto, a construção e conservação das ligações entre emigrantes e países de origem assumem particular relevância para as instituições estatais e para as associações de emigrantes, cujo objetivo central assenta, em termos gerais, na manutenção da cultura de origem do migrante e no desenvolvimento de uma identidade coletiva entre os mesmos. Trata-se de entidades que assumem, frequentemente, uma dupla função mediadora: entre os emigrantes e as instituições oficiais, e entre o contexto social, cultural e político do país de acolhimento e, por exemplo, os portugueses no exterior (Marques, Góis, 2013). O estudo das associações de migrantes tem mostrado a crescente complexidade da realidade dessas organizações e as múltiplas funções que desempenham nos contextos dos países de acolhimento e de origem. Menos estudado têm sido a evolução e a diversidade da paisagem organizativa dos migrantes, a qual apresenta uma elevada heterogeneidade em termos de dimensão, organização, história, função, perfil sociodemográfico dos associados, etc.

Neste artigo pretendemos: a) conhecer as formas organizativas da diáspora portuguesa global; b) a evolução do modelo organizacional das associações recémformadas (após 2000) em comparação com as associações formadas anteriormente; c) mapear as associações da diáspora portuguesa à escala global; e, finalmente, d) construir uma tipologia, em sentido weberiano (Bailey, 1994). Conhecer quais são as formas organizativas dos migrantes na atualidade, as suas configurações 
e espaços de ação, constitui uma tarefa central na análise das formas de ligação dos emigrantes aos seus países de origem. Torna-se, assim, relevante construir uma imagem atualizada destas organizações/associações que tenha em atenção que as formas organizativas dos migrantes são determinadas por múltiplos fatores, como as caraterísticas demográficas, econômicas e sociais dos migrantes, as suas concentrações residenciais, as suas origens e opções religiosas, as suas orientações políticas, etc., e, ainda, pela função que exercem na integração dos seus membros nas sociedades de destino e na manutenção da identidade da sociedade original (cf., entre outros, Caselli, 2010; Sardinha, 2009; Schrover, Vermeulen, 2005).

\section{Políticas e práticas de vinculação dos migrantes}

O estudo das políticas e práticas de vinculação dos migrantes é relativamente recente na literatura sobre migrações internacionais (Collyer, 2013; Gamlen, 2008; Lafleur, 2012; Waldinger, 2015). Os estudos existentes analisam, frequentemente de forma independente, as políticas dos Estados de origem para incluírem os seus cidadãos no exterior (isto é, as políticas de cidadania extraterritoriais ou de extensão de direitos; Bauböck, 1994) e as diferentes formas de relacionamento entre os migrantes e o país de origem. As análises existentes podem ser ancoradas em três domínios teóricos: i) no estudo das práticas transnacionais dos migrantes (Basch et al., 1994); ii) na discussão entre migração e desenvolvimento (Faist et al., 2011); iii) numa perspetiva normativa sobre a extensão dos direitos de cidadania aos emigrantes e respetivos descendentes (Bauböck, 1994, 2005; Lafleur, 2012).

Analisando o papel do Estado relativamente a estas questões, as políticas de engajamento têm sido das dimensões mais exploradas na questão dos emigrantes. A maioria dos estudos analisa a extensão das políticas dos Estados de origem face às suas comunidades no exterior, como uma forma de 'cidadania extraterritorial' (Bauböck, 1994; Collyer, 2013; Itzigsohn, 2000; Lafleur, 2012), em que o direito de voto no estrangeiro e a dupla cidadania são parte de uma estratégia do Estado para incluir emigrantes na sociedade nacional. Outros estudos reconhecem a diversidade das políticas e das práticas de vinculação/engajamento conduzidas pelos Estados - acrescentando a análise das atividades socioculturais, políticas e econômicas através das quais o engajamento do migrante é procurado e promovido (Østergaard-Nielsen, 2003) - ou as práticas burocráticas, políticas de investimento, serviços do Estado no exterior e políticas simbólicas, destinadas a "garantir que os migrantes permaneçam ininterruptamente conectados ao país de origem numa relação de longa distância" (Levitt, de la Dehesa, 2003, p. 587).

Gamlen (2006, 2008) classificou as políticas de vinculação segundo o seu contributo na expansão da cidadania, para além das fronteiras territoriais, e distinguiu dois tipos de políticas de vinculação: a) 'políticas de construção de comunidades', que promovem a manutenção e o reconhecimento das comunidades na diáspora; e b) 'políticas de capacitação' e mecanismos, que 
promovem a extensão de privilégios de pertença a estas comunidades de diáspora. Estes tipos de políticas de vinculação focam-se em formas estatais ou institucionais para alcançar os emigrantes. Não levam em consideração as práticas de interação que os próprios emigrantes constroem e mantêm com o seu país de origem, nem atendem ao uso efetivo que os emigrantes fazem das políticas de vinculação desenvolvidas pelo Estado. As políticas são, neste prisma, exclusivamente unidirecionais: do Estado para os indivíduos e excluem, numa perspetiva algo conservadora, a potencialidade existente nas políticas de vinculação que podem assumir um espetro longo e articular-se com as práticas existentes atualmente no âmbito das tecnologias de informação e comunicação.

Da perspetiva dos migrantes, as relações mantidas com os países de origem têm sido enquadradas nas 'práticas transnacionais dos migrantes' (Fibbi et al., 2008; Marques, Góis, 2008). Estas práticas são frequentemente vistas como uma forma de 'globalização a partir de baixo' (Smith, Guarnizo, 1998) em que o Estado desempenha um papel minoritário, mas não insignificante (Itzigsohn, 2000; Østergaard-Nielsen, 2003). O envolvimento em atividades políticas e na esfera econômica através da promoção do desenvolvimento da pátria (ver, de Haas, 2006) tem sido, a este nível, um dos temas mais estudados. A estabilização e institucionalização destas práticas contribui para a formação de comunidades transnacionais nas quais os migrantes se ligam à sociedade de origem através de "laços densos e estáveis ao longo do tempo e do espaço" (Faist, 2000, p. 22). As diásporas constituem uma das formas que estas sociedades transnacionais podem assumir (Faist, 2000).

Ainda que se reconheça que as diásporas possam constituir 'comunidades' distintivas (Cohen, 1997), assinala-se que estas "são definidas não por essência ou pureza, mas pelo reconhecimento de uma necessária heterogeneidade e diversidade" (Hall, 1990, p. 235). É, assim, relevante trazer para esta discussão o fenômeno da «homogeneização» dos emigrantes ou descendentes, quando se fala nas redes de diáspora, fazendo crer que existe apenas um tipo de emigrante em diáspora, por país de origem. Em prol da produção de uma identidade coletiva, as diferenças - regionais, culturais, religiosas, sociais, entre outras - das comunidades migrantes tendem a ser anuladas, construindo-se um modelo 'tipo ideal' desta comunidade em diáspora (Noirjean, Vodoz, 2009, p. 15) que, na prática, é muito mais segmentada e plural. Faz, por isso, sentido adotar a noção de Brubaker (2005, p. 13) de que "em vez de falar de 'uma diáspora' ou 'a diáspora' como uma entidade, um grupo limitado, um fato etnodemográfico ou etnocultural, pode ser mais produtivo, e certamente mais preciso, falar de posturas, projetos, reivindicações, expressões idiomáticas, práticas, etc, na diáspora". Estas podem ser de variada natureza e assumir diferentes caraterísticas, originando, assim, configurações de diáspora heterogêneas, em função, por exemplo, da sua permanência histórica, do seu grau de dispersão no espaço, da intensidade da sua orientação para o país de 
origem e da manutenção das fronteiras identitárias (Brubaker, 2005). Autores como Dijkzeul e Fauser (2020) chamam a atenção para o fato de a interligação entre as organizações da diáspora e as políticas internacionais dos Estados não ter sido objeto de um estudo completo. No âmbito deste artigo pretendemos contribuir para esta ligação através do estudo das associações de emigrantes portugueses e descendentes à escala global interligando dois campos que parecem desconetados, mas que, como procuraremos demonstrar, encerram um enorme potencial para uma efetivação de políticas de internacionalização dos Estados, das suas empresas e de outras organizações (ex. Universidades, Municípios, etc.).

\section{Metodologia}

Esta investigação pressupôs como objeto analítico as formas de associação e mobilização da Diáspora portuguesa à escala global. Os dados resultam de uma revisão sistemática de literatura, da criação de uma base de dados com as informações publicamente disponíveis de associações portuguesas no exterior do território nacional e da aplicação de um inquérito por questionário em formato online realizado no ano de 2016. No total foram realizados, através de diferentes canais de comunicação, 4.525 contatos tendo obtido resposta a 530 inquéritos.

\section{O movimento associativo português em diferentes países}

O movimento associativo acompanha os diferentes fluxos migratórios nacionais. A história contemporânea portuguesa é marcada por dois grandes ciclos migratórios: o ciclo transatlântico e o ciclo intraeuropeu. O ciclo transatlântico desenvolveu-se ao longo do século XIX, atingiu o seu apogeu na viragem do século XIX-XX e, no que concerne à emissão massiva de emigrantes, entrou em declínio no período entre as duas grandes guerras. Desde o final dos anos 50 até 1974 a atração exercida pela França e, em menor grau, pela Alemanha, domina completamente a emigração portuguesa. Assim, do milhão e quatrocentas mil saídas verificadas entre 1962 e 1974, 75\% dirigiram-se para estes dois países, respetivamente $62 \%$ para a França e $13 \%$ para a Alemanha. Esta viragem para as migrações intraeuropeias não mais abandonou a história da emigração portuguesa. Ainda assim há importantes movimentos migratórios portugueses em direção a outros destinos de que se destacam as antigas colónias portuguesas em África ou a África do Sul' ${ }^{1}$. Assim, é natural que o número de associações da comunidade portuguesa em diáspora seja particularmente significativo nos países que registraram um maior afluxo de portugueses (Brasil, França, EUA, Canadá). Importa, por isso, olhar com atenção particular para o que se sabe sobre o movimento associativo, através da

\footnotetext{
1 Há uma ampla bibliografia sobre a história da emigração portuguesa. Para uma síntese ver BAGANHA, Maria Ioannis; GÓıS, Pedro. Migrações internacionais de e para Portugal: o que sabemos e para onde vamos?. 1999 e GÓIS, Pedro; MARQUES, José Carlos. Retrato de um Portugal migrante: a evolução da emigração, da imigração e do seu estudo nos últimos 40 anos. e-cadernos CES, n. 29, 2018.
} 
análise de uma seleção de estudos realizados sobre as associações portuguesas no exterior. Comecemos esta análise pelo mais significativo e histórico destino migratório lusitano até ao último quartel do século XX: o Brasil.

No Brasil, às associações assistencialistas e educativas/literárias criadas no século XIX, vieram juntar-se, no séc. XX, as associações regionais, os grupos folclóricos e desportivos e as câmaras de comércio. Algumas destas associações foram, paulatinamente, redefinindo os seus objetivos e alargando o público alvo, transformando-se, nalguns casos, em associações sociais e desportivas dirigidas a toda a população independentemente da sua nacionalidade (por exemplo, a Portuguesa dos Desportos de São Paulo) (Melo, Silva, 2009). Em muitos casos não conseguem renovar-se, devido, sobretudo, a dois motivos: primeiro, a ausência de novos migrantes e, concomitantemente, de novos associados, o que contribui para o processo de envelhecimento das associações; segundo, a localização das suas sedes em áreas urbanas para onde não vão os novos migrantes, faz com que a renovação dos fluxos migratórios lusos ocorra, em paralelo, com o envelhecimento das associações. Podemos encontrar exemplos destas associações em cidades brasileiras como São Paulo ou Rio de Janeiro, se pensarmos em fluxos migratórios mais antigos.

Em França, Muñoz (2002) distingue quatro momentos na criação cultural portuguesa nos últimos 40 anos (realizada, sobretudo em contexto associativo): 1) os anos 1960, em que o movimento associativo foi dominado por iniciativas da cultural popular (futebol, folclore e festas); 2) os anos 1970 que correspondem a um período de organização e de luta dos imigrantes contra as guerras coloniais portuguesas e em defesa das lutas dos trabalhadores em França; 3) os anos 1980, de estabilização da imigração e de desenvolvimento e diversificação do movimento associativo português; 4) os anos 1990 que testemunham a chegada dos descendentes de imigrantes nascidos em França ao movimento associativo e a sua dissidência relativamente às associações dos seus pais (através de criação de organizações autônomas, ou da adesão a associações francesas ou de outras comunidades imigrantes). Adotando uma divisão temporal distinta, Cravo (1995) considera três momentos do movimento associativo português em França: entre 1960 e 1974, entre 1974 e 1980 e após 1986: 1) o objetivo principal das associações era a manutenção e redescoberta do patrimônio cultural que o imigrante trazia consigo, com a esperança de regressar um dia ao seu país de origem; 2) a dinamização do movimento associativo é acompanhada pela criação de estruturas que procuram federar as múltiplas associações que foram sendo criadas e; 3) assistindo-se a uma abertura das associações portuguesas à sociedade francesa (testemunhado, por exemplo, pela criação de associações franco-portuguesas) e às outras comunidades imigrantes (Cravo, 1995).

O movimento associativo na Alemanha tem igualmente uma forte expressão, existindo, em 2008, pelo menos 196 associações. Destas 17 são Missões Católicas, 
39 Grupos Folclóricos e 140 Associações Recreativas e Culturais (Embaixada de Portugal em Berlim, 2008, apud Pinheiro, 2010). À semelhança do que sucede noutros países, as Associações recreativas e culturais desenvolvem um conjunto variado de atividades, incluindo atividades desportivas, folclóricas e outras de natureza cultural (Pinheiro, 2010). A dispersão das associações pelo território alemão espelha a distribuição da população portuguesa, existindo um maior número de associações nos centros industriais da Alemanha ocidental (Renânia do Norte-Vestefália, Baden-Vurtemberga, Hesse e Hamburgo), onde se concentra, também, a maioria dos portugueses. Segundo Pinheiro (2010), trata-se, na maioria dos casos, de associações com menos de 100 membros e com recursos financeiros limitados.

O movimento associativo na África do Sul desenvolveu-se, em particular, a partir do decênio de 1960, altura em que a emigração portuguesa para este país se torna mais intensa (apesar de já em 1908/09 existir a Associação Lusitana de Socorros Mútuos em Fordsburg). Uma parte significativa destes migrantes tinham origem na ilha da Madeira que, por não ter participado fortemente no plano de industrialização nacional dos anos 1960, não era capaz de criar emprego e contribuía para a expulsão de um número significativo de cidadãos. Parte significativa destas associações concentra-se na cidade de Joanesburgo, onde também se localiza uma importante comunidade lusa. Entre 1970 (em especial a partir do processo de descolonização português) e 1990 existiam na cidade aproximadamente 30 associações, o que levou alguns autores a reconhecerem a fragmentação da comunidade portuguesa em torno de associações de cariz regionalista (Bessa, 2009). A análise da realidade do movimento associativo em toda a África do Sul indica, contudo, que esta fragmentação não constitui uma caraterística de todo o movimento associativo sul-africano e que a caraterística central da fundação das associações é de natureza étnica e não regional. Um caso especial é o das Academias de Bacalhau, iniciadas em 1968. Trata-se de uma forma associativa "sem sedes fixas e com normas simples, (...) [que] são hoje um caso inédito de longevidade e de expansão" (Bessa, 2009, p. 129). Para além do aspecto relativo à confraternização em torno de uma refeição que tem por prato principal precisamente o Bacalhau, estas Academias procuram "promover o prestígio, a cultura e os valores lusos no país de acolhimento e as relações com outras comunidades" (Bessa, 2009, p. 127).

A dimensão do movimento associativo português nos EUA parece confirmar a asserção feita, em 1831, por Tocqueville de que "a América é o país do mundo em que se tirou maior partido da associação e em que se aplicou esse poderoso meio de ação a uma diversidade maior de objetos" (2005, p. 219). Existem associações iguais às de outros países de acolhimento, como a França ou o Brasil, onde os portugueses se encontram para ver futebol, conviver à mesa com gastronomia portuguesa e ainda têm uma (ou mais) equipes amadoras de futebol e/ou um rancho folclórico. Estas, porém, coexistem com outras que surgiram 
como resultado de uma redefinição das ideologias americanas e portuguesas em relação às suas populações migrantes, nomeadamente, a Prince Henry Society em New Bedford (Feldman-Bianco, 1992). Esta organização assemelha-se ao Rotary Club e é formada por profissionais liberais, industriais e comerciantes imigrantes e luso-americanos com objetivos de enaltecimento da cultura portuguesa de 'elite' na região e a condição dos seus associados. Simultaneamente, o objetivo é contribuir para a alteração da imagem dos portugueses na região, "de camponeses e pescadores envolvidos em rituais de religiosidade popular" (Feldman-Bianco, 1992, p. 44).

\section{Formas de associação dos portugueses na diáspora - uma análise contemporânea}

Conhecer as formas de organização dos emigrantes que se encontram dispersos pelo mundo é uma tarefa complexa e recheada de obstáculos. A forma mais comum de chegar ao contato com as suas formas associativas é, como reconhecem Meyer et al. (2016, p. 205), através de "redes sociais/institucionais, incluindo os websites das associações profissionais de migrantes, registros consulares e diplomáticos, as listas alumni das instituições de ensino superior e os contatos interpessoais dos emigrantes, que podem ser obtidos através do efeito de bola-de-neve" ${ }^{2}$. Contudo, mesmo o cotejamento de todas as fontes mencionadas não garante a obtenção de um mapa completo das diásporas e das suas formas associativas. A análise que se apresenta de seguida testemunha estas limitações e é, por isso, incompleta e parcial.

Tabela 1 - Caraterísticas das associações de emigrantes portugueses

\begin{tabular}{c|c|c}
\hline & $\mathrm{N}$ & $\%$ \\
\hline Período de criação & $(n=943)$ & \\
\hline Até 1959 & 127 & 13,5 \\
\hline $1960-1979$ & 230 & 24,4 \\
\hline $1980-1999$ & 317 & 33,6 \\
\hline $2000-2016$ & 269 & 28,5 \\
\hline Continente & $(n=2.894)$ & \\
\hline África & 130 & 4,5 \\
\hline América & 1058 & 36,6 \\
\hline Europa & 1607 & 55,5 \\
\hline Outros & 99 & 3,4 \\
\hline
\end{tabular}

2 A amostra por bola de neve é uma técnica de amostragem não probabilística onde os indivíduos selecionados para serem estudados convidam novos participantes da sua rede de amigos e conhecidos. 


\begin{tabular}{l|c|c}
\hline Tipo de associação & $(n=1.566)$ & \\
\hline Econômica & 78 & 5,0 \\
\hline Social e/ou Cultural & 825 & 52,7 \\
\hline Esportiva & 204 & 13,0 \\
\hline Religiosa & 51 & 3,3 \\
\hline De caridade/beneficência & 51 & 3,3 \\
\hline $\begin{array}{l}\text { Página web de promoção da cultura } \\
\text { portuguesa e/ou informativa }\end{array}$ & 144 & 9,2 \\
\hline $\begin{array}{l}\text { Profissional, empresarial, de } \\
\text { estudantes, investigadores }\end{array}$ & 83 & 5,3 \\
\hline Outra & 130 & 8,3 \\
\hline
\end{tabular}

Fonte: Mapeamento das Associações Portuguesas no Exterior, 2016.

O levantamento efetuado testemunha a extensão do movimento associativo por todos os continentes, acompanhando de perto os diferentes fluxos migratórios que marcaram a história nacional e afirmando-se como uma das mais significativas e marcantes "redes informais ou institucionalizadas que os portugueses criaram no contexto emigratório" (Melo, Silva, 2009, p. 35).

O período de criação das associações segue, de forma geral, os períodos da emigração portuguesa. O ciclo transatlântico da emigração portuguesa levou à criação de um número elevado de associações, maioritariamente (89,8\%) nos principais destinos da emigração portuguesa pré-1960 nos continentes norte e sul-americanos, em especial no Brasil (44,9\%) e nos EUA (37,8\%). A criação de associações nestes dois continentes continuou a ser intensa durante as quatro décadas seguintes, tendo, contudo, sido suplantada pela intensa criação associativa nos países europeus, em resultado do fluxo emigratório português dos anos de 1960 e 1970 e da estabilização de comunidades portuguesas nesses países, sobretudo em França e na Alemanha, durante as duas décadas seguintes. Durante os primeiros anos do século XXI a Europa continua a verificar o maior número de associações criadas em resultado da nova intensificação da emigração para os países deste continente. A partir da década de 1960 a criação de associações de emigrantes nos continentes americanos reduz-se de forma assinalável, consequência da diminuição da emigração para estes destinos (não obstante, um movimento crescente verificado nos últimos anos) e da estabilização do movimento associativo português nestes países.

A análise mais pormenorizada destes dados confirma, no caso europeu, a relevância da emigração portuguesa no passado recente, em especial para a França que, no levantamento realizado, registra $26 \%$ do total de associações contabilizadas na Europa. Os restantes países, com mais de uma centena de associações, são igualmente importantes destinos da emigração portuguesa. De assinalar o caso espanhol, em que a numerosa presença de portugueses (107.226, 
em 2015 (Pires et al., 2016)) não se traduziu no desenvolvimento de uma densa rede de organizações associativas.

\section{Tipos de associações: uma proposta de classificação contemporânea}

Reconhece-se que as atividades das organizações de migrantes se desenvolvem, habitualmente, na interação entre o país de acolhimento e o país de origem e que a consideração dos contextos que formam o ambiente das associações permite compreender de forma mais completa as suas dinâmicas e formas de ação. Tão relevante como analisar o potencial e os limites das associações/organizações de migrantes para a integração e/ou manutenção identitária dos migrantes, é conhecer os tipos de organizações criadas pelos migrantes e a forma como o Estado as inclui no âmbito da sua política dirigida às comunidades, no caso em estudo, portuguesas.

Nos diferentes períodos referidos anteriormente (Tabela 1), o tipo de organizações criadas não apresenta oscilações significativas. Em cada um dos quatro períodos domina, ainda que de forma decrescente, a criação de organizações de cariz social e cultural ou esportiva. No global, este tipo de associações representa entre 72,6\% (entre 1960 e 1979) e 51,0\% (a partir de 2000) das associações criadas em cada período. No último período, nota-se a diversificação do tipo de organizações criadas, surgindo em maior número associações com existência desmaterializada (ex. sem sede física) e associações com fins econômicos, científicos ou profissionais (estas últimas em contínuo com o registrado no período anterior). Ainda que a evolução das associações se tenha adaptado à estrutura de oportunidades existente em cada um dos países de destino, encontra-se, em praticamente todos os países, uma forte presença de associações ligadas às atividades sociais, culturais, recreativas e esportivas, assim como associações de abrangência nacional e de alcance regional. Esta primeira regularidade é um dos sinais das distâncias culturais que se expatriam em conjunto com o movimento emigratório. Estas reproduzem as características dos emigrantes e as suas culturas e interesses.

As formas de mobilização coletiva tradicionais - associações e organizações, câmaras de comércio, academias (in)formais ou confrarias, clubes sociais ou clubes esportivos - bem como as mais recentes - societies, redes alumni, grupos informais no seio de redes sociais ou outros - têm uma posição privilegiada de mediação na referida interseção entre o país de origem e o país de acolhimento. Como referem Grassi e Melo (2007) este tipo de organizações exerce um duplo mecanismo de inclusão social: tanto estão próximas da comunidade de origem, como também alcançam a comunidade de destino. A este aglomerado de organizações, (quase sempre) com origem na dinâmica da sociedade civil, acrescentam-se organizações mais formais de representação institucional onde se incluem as embaixadas, a rede consular, a rede da Agência para o Investimento e Comércio Externo de 
Portugal (AICEP), as representações das regiões autônomas ${ }^{3}$ e as representações de institutos públicos portugueses com exposição no exterior do território nacional. Em conjunto, estas organizações e instituições constituem-se como núncios permanentes da sociedade e do Estado português no exterior e situam-se na interface de várias redes da diáspora e de Portugal.

O mapeamento das associações, realizado em 2015-16, permitiu aferir que os tipos de organizações descritas na literatura continuam a estar presentes nos diferentes contextos da emigração portuguesa. Em geral, pode afirmar-se que as associações encontradas e as atividades por elas desenvolvidas são de natureza diversa. As associações foram classificadas de acordo com a tipologia enunciada neste capítulo e tendo em consideração que poderiam ter mais do que uma inserção, como, por exemplo, associações socioculturais e esportivas. Sempre que possível, foi colocada em primeiro lugar a característica que parecia conferir mais identidade à associação. Não foi possível, porém, enquadrar a totalidade das associações, pois em muitos casos não se conseguiu a informação necessária, designadamente quando apenas se obteve o endereço e/ou a data da fundação e/ou endereços web que (já) não se encontravam disponíveis no momento da consulta. O total das associações classificadas foi de 1.566 na característica principal e 419 na secundária ou complementar. Como referido anteriormente, as associações de cariz social e cultural são as que se encontram mais representadas, constituindo 52,7\% do conjunto das associações, das quais foi possível obter informações que permitissem a sua classificação. Embora com um contingente menor, mas numa importante proporção, encontram-se as associações esportivas. Há diversas associações que são simultaneamente sociais/culturais e esportivas, podendo incluir clubes de futebol amadores, ou a prática de outra atividade esportiva. Trata-se das associações tradicionalmente caracterizadas como 'sociais, culturais e esportivas'. Nos dados recolhidos, 96,4\% das associações esportivas eram também socioculturais, e $55,2 \%$ das associações socioculturais eram igualmente esportivas. O número de associações sociais, culturais e/ou esportivas criadas tem vindo a decair ao longo do tempo, passando de 86,3\%, entre 1960 e 1979 , para $60,1 \%$, a partir do ano 2000 . Tal constitui, certamente, um reflexo da modificação da realidade migratória nacional, assim como da alteração dos modelos associativos testemunhada, sobretudo, a partir do início do século XXI (cf. Góis, Marques, 2018).

Evidência desta alteração encontra-se, por exemplo, na criação, sobretudo a partir do ano 2000, de associações profissionais, empresariais ou de estudantes, e de associações que assentam o desenvolvimento das suas atividades nas novas tecnologias de informação e comunicação. Uma ilustração adicional destas alterações encontra-se no aumento progressivo das associações com presença parcial ou exclusiva no espaço cibernético. Assim, enquanto a maioria das

\footnotetext{
3 Região autônoma da Madeira e Região Autônoma dos Açores.
} 
associações criadas até ao ano final do século XX tem apenas uma presença física $(66,5 \%)$, ou conjuga esta com uma presença online $(78,3 \%)$, as associações criadas a partir do ano 2000 têm, maioritariamente, uma existência apenas online (81,0\%). Cada vez mais significativas tenderão a ser as organizações em torno de uma página de Facebook ou de um website, para o compartilhamento de informações diversas sobre o país de origem e o de acolhimento, divulgação de oportunidades de trabalho, descrição de experiências migratórias, e dinamização de convívios.

Aos tipos tradicionais de associação referidas na literatura (social, esportiva e cultural, religiosa, de beneficência e políticas), o levantamento realizado permitiu acrescentar associações com caraterísticas diferentes e que permitiram avançar para uma conceptualização de uma tipologia das associações portuguesas contemporâneas. Esta tipologia procurou, assim, reter os elementos presentes nas associações mais antigas e, simultaneamente, aludir às especificidades de formas associativas mais recentes. Ainda que partindo de elementos presentes na realidade associativa portuguesa, a tipologia proposta tem, sobretudo, um valor heurístico, exigindo, como referem Barton e Lazarsfeld (1955, apud Kluge, 1999, p. 61), "ser sujeita a uma análise detalhada numa fase posterior".

\section{Para uma tipologia do movimento associativo português}

O estudo das caraterísticas, objetivos e campos de intervenção do movimento associativo dos portugueses no exterior permite conceber a existência de diferentes tipos de associações: tradicionais, religiosas, culturais, digitais e de conhecimento. Ainda que cada tipo apresente particularidades próprias, é possível identificar elementos comuns aos diferentes tipos.

O primeiro tipo de associação identificado refere-se ao que denominamos 'associações do tipo tradicional'. Trata-se de associações (mais) tradicionais, ou seja, com uma sede física, com associados pagadores de quotas, e com associados frequentadores da sede, geralmente com um pequeno bar. Promovem convívios e festas em ocasiões especiais e constituem um local de realização de festas familiares (ex. aniversários) dos seus membros. Possuem acesso à televisão portuguesa, com acesso a canais esportivos de subscrição (como, a Sport TV) que agrega a comunidade, e outros membros próximos, em dias de jogos da seleção nacional, mas separa a comunidade em dias de jogos de campeonato entre diferentes clubes, gerando pequenos conflitos clubistas. Por vezes, têm (ainda) um rancho folclórico e preservam memórias de um Portugal que corresponde 'ao tempo' dos seus associados. Fazem parte deste tipo, subtipos mais específicos como, as casas mais regionalistas (da Madeira, dos Açores, do Alentejo, etc.) e as casas dos clubes de futebol portugueses. Em vez do rancho folclórico, podem existir bandas ou grupos de corais. A sua função principal é criar uma rede social de proximidade para os portugueses que estão longe. No fundo é uma "casa longe de casa" ou uma "terra longe da terra". 
O segundo tipo de associações, designado de 'religiosas', encontram-se ligadas à Igreja Católica (ou mais recentemente às Igrejas Evangélicas) e assentam a sua missão na manutenção de vínculos e de uma cultura religiosa. Promovem uma caridade religiosa, protegendo os mais desfavorecidos ou apoiando momentaneamente os que carecem de ajuda. Exemplos deste tipo de associações são as missões católicas, as irmandades, os grupos que agregam catequistas ou que se formam em torno das paróquias portuguesas no estrangeiro.

As associações culturais constituem um terceiro tipo. Baseiam-se, sobretudo, na promoção ou preservação da cultura portuguesa ou das culturas portuguesas, no plural. São associações de subtipos muito diversos e dependem muitas vezes da distância (mediada em tempo/espaço) em relação a Portugal, ou seja, dependem do momento em que foram formadas e das geografias onde se situam. Incluímos aqui as dinâmicas das associações ligadas à preservação, divulgação e promoção da língua portuguesa, mas, também, as associações ligadas à gastronomia (como as confrarias ou as academias do bacalhau) e as dedicadas a espaços específicos de convivialidade gastronômica, como por exemplo a associação "Amigos da Caldeirada de Durban", na África do Sul.

Um quarto tipo de associações são as intituladas de 'digitais', e assumem as caraterísticas que na literatura são próprias das "Digital Diaspora Networks". Assentam-se nas novas redes sociais digitais, ou em sites na Internet que agregam pessoas, objetivos e ideias, com base numa multiplicidade de critérios: terras de origem (ex. Sourenses pelo mundo), regiões onde vivem (ex. portugueses em Southend-On-Sea), eventos culturais particulares, etc. Agregam portugueses no estrangeiro numa escala nacional, supranacional ou global. Incluímos aqui grupos recentes ou já tradicionais, efêmeros e mais permanentes, no facebook ou instagram. Estas associações raramente possuem uma configuração estatutária tradicional ou uma sede física.

Um último tipo de associações, designadas de 'associações de conhecimento', referem-se às associações ou redes baseadas no conhecimento, conhecidas na literatura por "Knowledge Diaspora Networks". Representam um novo tipo de associações baseadas na partilha de conhecimento e na necessidade de construir e manter o capital social ou o capital cultural. Os melhores exemplos portugueses são a Associação de Pós-Graduados Portugueses na Alemanha (Asppa); Portuguese Association of Researchers and Students in the UK (Parsuk); Association des Diplômés Portugais en France (Agrafr); a Associação Portuguesa de Estudantes, Investigadores e Graduados na Bélgica, Holanda e Luxemburgo (APEI Benelux) ou a Portuguese American Post-Graduate Society (Paps), mas também se incluem neste tipo, a 'Diáspora dos enfermeiros'; Confederações e Câmaras de comércio; Clubs e societies. Neste tipo de associações prevalece uma certa formalização estatutária e uma estrutura hierárquica bem identificada. As formas de comunicação são induzidas pelo potencial das tecnologias de informação e 
comunicação. Promovem regularmente atividades que permitem desenvolver os seus objetivos, incluindo aquelas pensadas para agregar diversas associações, que possuem objetivos similares e estão presentes em diferentes contextos regionais.

Como já assinalado por Melo e Silva (2009, p. 56), trata-se de

novos formatos associativos que prescindem das bases físicas e locais e buscam estabelecer redes transnacionais de cooperação entre emigrantes portugueses e seus descendentes radicados em diferentes países. Essas redes de relacionamento valem-se de uma visão da emigração como diáspora e promovem encontros e debates no espaço virtual, além de eventos ocasionais em cidades com importantes contingentes migrantes.

\section{Considerações finais}

A presença de 2,5 a 5 milhões de portugueses e descendentes de portugueses nos diversos países do mundo encontra-se estreitamente associada ao desenvolvimento de variadas formas de mobilização social, política, cultural e económica (Dumont, 2010; Simões, Melo-Pfeifer, 2010). O movimento de associação dos portugueses residentes no exterior e dos seus descendentes é, na sua génese, um mecanismo de narração da própria história das migrações portuguesas. Ao procurarem no exterior manterem vínculos com os seus compatriotas buscam, no essencial, manterem um vínculo com o país de origem (ou de origem dos seus antepassados). Fazem-no de múltiplas formas, sob variados tipos de organizações e/ou instituições, mas acompanhando sempre as configurações e tecnologias de comunicação disponíveis em cada momento e, nesse sentido, mostram a sua resiliência face à distância física de Portugal.

As diásporas de hoje são também (mas não apenas), como bem as definem Mahroum, Eldridge e Daar (2006), redes digitais do conhecimento que se dispersam globalmente, mas mantêm um contato quotidiano com o país de origem. Outros termos são usados para definir as atuais redes: redes de intelectuais (intellectual diaspora networks), diáspora do conhecimento (diaspora knowledge networks), diásporas de transferência de conhecimento (knowledge transfer networks). Todas estas denominações configuram, em nosso entender, o aparecimento e consolidação de um novo tipo de formas associativas, quase sempre ligadas à rede digital e às tecnologias de informação e comunicação. Uma espécie de movimento associativo 4.0 em que as ligações em rede e pela rede não são necessariamente físicas, mas, nem por isso, ligam menos os participantes. O desenvolvimento deste novo formato de associações, em rede e pela rede, formais ou informais, e de escala local, regional, nacional ou transnacional, deve ser encarado como uma oportunidade, tanto mais que estas podem potenciar ainda mais o já reconhecido papel que as diásporas podem assumir, nomeadamente, no desenvolvimento socioeconômico e na integração e coesão social entre os que residem em Portugal e os residentes no exterior. 
Nos últimos anos tem-se assistido à intensificação de políticas e iniciativas direcionadas para a promover o engajamento das comunidades nas diásporas e, deste modo, aproveitar o potencial de desenvolvimento existente para a ampliar a relação entre a sociedade portuguesa e as suas várias gerações de emigrantes. O reconhecimento das diásporas enquanto recurso multidimensional tem, neste âmbito, sido visto como uma oportunidade por parte dos governos, sociedade civil, entidades municipais, associações profissionais e empresariais, sindicatos, empresas entre outros. As formas de mobilização de grupos de emigrantes apresentam oportunidades importantes de desenvolvimento de práticas transnacionais de diferente natureza: política, econômica, cultural e social. Ou seja, de atividades que aprofundem o inter-relacionamento entre os locais de residência dos emigrantes e os seus locais de origem (ou de origem dos seus antepassados, no que se refere aos descendentes de emigrantes). É ainda reduzido e limitado o conhecimento sobre as (múltiplas) formas de relacionamento entre os Estados de origem e as suas diásporas. O que se conhece aponta para uma grande diversidade de políticas de vinculação conduzidas pelos Estados, integradas com diferentes graus de intensidade, atividades socioculturais, políticas e econômicas. Todas estas atividades procuram criar condições para que os migrantes mantenham uma relação, mesmo que a distância, com o país de origem ou ancestral, e que se envolvam com este país, a partir dos países em que se encontram a residir.

Como referido noutro local (Marques, Góis, 2014), uma das características principais destas políticas é o fato de serem construídas, sobretudo, pelos Estados ou instituições do país de origem. Não levam, por isso, em consideração as práticas de interação que os próprios emigrantes constroem e mantêm com o seu país de origem ou a teia de relações que as associações estabelecem a outros níveis: entre associações no estrangeiro; com o território português numa escala local, regional ou nacional; com as instituições e associações em Portugal. Estas práticas de vinculação têm sido frequentemente descritas em termos de 'práticas transnacionais' dos migrantes nas esferas política, econômica, social, cultural, ou no envolvimento de atividades promotoras de desenvolvimento nos contextos de origem. A análise das formas de associação dos portugueses no exterior evidencia uma grande heterogeneidade em termos de consolidação estrutural, de dimensão, de objetivos e de atividades desenvolvidas. No essencial, todas as formas associativas de migrantes reproduzem, em maior ou menor grau, a diversidade das caraterísticas das comunidades migrantes que as originaram ou que as mantêm ativas. A existência de tipos diversos de associações não é, neste sentido, uma surpresa, mas a sua estruturação numa matriz tipológica ajuda a perceber e a construir dinâmicas de relacionamento futuro. 


\section{Referências bibliográficas}

BAILEY, Kenneth D. Typologies and taxonomies: An introduction to classification techniques. London: Sage, 1994.

BASCH, Linda; SCHILLER, Nina Glick; SZANTON, Blan Cristina (eds.). Nations unbound: transnational projects, postcolonial predicaments, and deterritorialized nation-states. Amsterdam: Gordon and Breach, 1994.

BAUBÖCK, Rainer. Transnational Citizenship: Membership and Rights in International Migration. Aldershot: Edward Elgar, 1994.

BAUBÖCK, Rainer. Expansive Citizenship: Voting beyond Territory and Membership. Political Science and Politics, v. 38, n. 4, p. 683-687, 2005.

BESSA, Paulo. A Comunidade Lusíada em Joanesburgo. Porto: CEPESE/Fronteira do Caos, 2009.

BRUBAKER, Rogers. The 'diaspora' diaspora. Ethnic and Racial Studies, v. 28, n. 1, p. 1-19, 2005.

CASELLI, Marco. Integration, Participation, Identity: Immigrant Associations in the Province of Milan. International Migration, v. 48, n. 2, p. 58-78, 2010.

COHEN, Robin. Global Diasporas: An Introduction. London: UCL Press, 1997.

COLLYER, Michael (ed.). Emigration Nations. Policies and Ideologies of Emigrant Engagement. Basingstoke: Palgrave Macmillan, 2013.

CRAVO, António. Les Portugais en France et leur mouvement associatif: 1901-1986. Paris: L'Harmattan, 1995.

DE HAAS, Hein. Engaging Diasporas: How Governments and Development Agencies Can Support Diaspora Involvement in the Development of Origin Countries. Oxford: International Migration Institute, 2006.

DIJKZEUL, Dennis; FAUSER, Margit. Introduction: Studying diaspora organizations in international affairs. In: Diaspora Organizations in International Affairs. London: Routledge, 2020, p. 1-24.

DUMONT, Antoine. L'état des recherches sur les associations de migrants internationaux. Revue européenne des migrations internationales, v. 26, n. 2, p. 117-137, 2010.

FAIST, Thomas (ed.). Transstaatliche Räume. Politik, Wirtschaft und Kultur in und zwischen Deutschland und der Türkei. Bielfeld: Transcript Verlag, 2000.

FAIST, Thomas; KIVISTO, Peter; FAUSER, Marit (eds.). The Migration-DevelopmentNexus: A Transnational Perspective. Basingstoke: Palgrave Macmillan, 2011.

FELDMAN-BIANCO, Bela. Saudade, imigração e a construção de uma nação (portuguesa) desterritorializada. Revista Brasileira de Estudos da População, v. 9, n. 1, p. 35-49, 1992.

FIBBI, Rosita; D'AMATO, Giani; HILLY, Marie-Antoinette (coords.). Pratiques Transnationales - Mobilité et Territorialités. Revue Européene des Migrations Internationales, número temático, v. 24, n. 2, 2008.

GAMLEN, Alan. Diaspora Engagement Policies: What are they, and what kinds of states use them? Oxford: University of Oxford, Centre on Migration, Policy and Society, 
Working Paper n. 32, 2006. Disponível em: <https:/www.compas.ox.ac.uk/wpcontent/uploads/WP-2006-032-Gamlen_Diaspora_Engagement_Policies.pdf $>$. Acesso em: 01.06.2014.

GAMLEN, Alan. The emigration state and the modern geopolitical imagination. Political Geography, n. 27, p. 840-856, 2008.

GRASSI, Marzia; MELO, Daniel. Portugal na Europa e a questão migratória: associativismo, identidades e políticas públicas de integração. ICS Working Paper(WP4-07), 2007. Disponível em: <http://www.ics.ul.pt/publicacoes/ workingpapers/wp2007/wp2007_4.pdf>. Acesso em: 01.06.2014.

HALL, Stuart. Cultural identity and diaspora. In: RUTHERFORD, Jonathan (ed.). Identity: Community, Culture, Difference. London: Lawrence \& Wishart, 1990, p. 222-237.

ITZIGSOHN, José. Immigration and the Boundaries of Citizenship: The Institutions of Immigrants' Political Transnationalism. International Migration Review, v. 43, n. 4, p. 1126-1154, 2000.

KLUGE, Susann. Empirisch begründete Typenbildung. Zur Konstruktion von Typen und Typologien in der qualitativen Sozialforschung. Opladen: Leske \& Budrich, 1999.

LAFLEUR, Jean Michele. Transnational Politics and the State. London: Routledge, 2012.

LEVITT, Peggy; DE LA DEHESA, Rafael. Transnational Migration and the Redefinition of the State: Variations and Explanations. Ethnic and Racial Studies, v. 26, n. 4, p. 587-611, 2003.

MAHROUM, Sami; ELDRIDGE, Cyntia; DAAR, Abdallah S. Transnational diaspora options: how developing countries could benefit from their emigrant populations. International Journal on Multicultural Societies, v. 8, n. 1, p. 25-42, 2006.

MARQUES, José Carlos; GÓIS, Pedro. Pratiques transnationales des Capverdiens au Portugal et des Portugais en Suisse. Revue Européenne des Migrations Internationales, v. 24, n. 2, p. 147-165, 2008.

MARQUES, José Carlos; GÓIS, Pedro. Portuguese emigrants and the State: An ambivalent relationship. In: COLLYER, Michael (ed.). Emigration Nations: the ideologies and policies of emigrant engagement. Houndmills: Palgrave Macmillan, p. 252-276, 2013.

MARQUES, José Carlos; GÓIS, Pedro. A emigração portuguesa contemporânea e o Estado: uma Nação dispersa, um Estado longínquo. População e Sociedade, n. 22, p. 55-71, 2014.

MELO, Daniel; SILVA, Eduardo Caetano da. Associativismo, emigração e nação: o caso português. In: MELO, Daniel; SILVA, Eduardo C. da (eds.). Construção da Nação e Associativismo na Emigração Portuguesa. Lisboa: Imprensa de Ciências Sociais, p. 31-69, 2009.

MEYER, Jean-Baptiste; MIAO, Fan Weng; ZHAO, Yue. Visualizing the Diaspora: New Options. In: CHIKANDA, Abel; CRUSH, Jonathan; WALTON-ROBERTS, Margareth (eds.). Diasporas, Development, and Governance. Heidelberg: Springer Verlag, p. 205-220, 2016. 
MUÑOZ, Marie-Claude. Le renouveau de la creation culturelle dans les associations portugaises. Hommes et Migrations, n. 1236, p. 82-92, 2002.

NOIRJEAN, Sophie; VODOZ, Luc. Diasporas et TIC: la territorialité en question L'exemple de la communauté des Albanais du Kosovo en Suisse. Lausann: CEAT, Rapport final, 2009. Disponível em: < https://infoscience.epfl.ch/record/143372/ files/Rapport_final_161209_SN.pdf>. Aceso em: 01.06.2014.

ØSTERGAARD-NIELSEN, Eva (ed.). International migration and sending countries: perceptions, policies and transnational relations. Basingstoke: Palgrave Macmillan, 2003

PINHEIRO, Teresa. Vernetzte Identitäten: Repräsentationen portugiesischer Emigration im deutschsprachigen Internet. In: PINHEIRO, Teresa (ed.). Portugiesische Migrationen: Geschichte, Repräsentation und Erinnerungskulturen. Wiesbaden: Verlag für Sozialwissenschaften, 2010, p. 175-196.

PIRES, Rui Pena; PEREIRA, Cláudia; AZEVEDO, Joana; ESPÍRITO-SANTO, Inês; VIDIGAL, Inês. Emigração Portuguesa. Relatório Estatístico 2016. Lisboa: Observatório da Emigração e Rede Migra, CIES-IUL, ISCTE-IUL, 2016.

SARDINHA, João. Immigrant Associations, Integration and Identity. Angolan, Brazilian and Eastern European Communities in Portugal. Amsterdam: Amsterdam University Press, 2009.

SCHROVER, Marlou; VERMEULEN, Floris. Immigrant Organisations. Journal of Ethnic and Migration Studies, v. 31, n. 5, p. 823-832, 2005.

SIMÕES, Ana Raquel; MELO-PFEIFER, Sílvia. Les associations d'immigrants comme des espaces d'apprentissage de l'intégration: une étude comparative en contexte portugais. Langue et Intégration-Dimensions institutionnelle, socio-professionnelle et universitaire. Bern: Peter Lang, 2010, p. 133-150.

SMITH, Michael P.; GUARNIZO, Luis. Transnationalism from below. New Brunswick, N.J.: Transaction Publishers, 1998.

SONG, Changzoo. Engaging the diaspora in an era of transnationalism. IZA World of Labor, n. 64, 2014. Disponível em: <https://wol.iza.org/uploads/articles/64/ pdfs/engaging-the-diaspora-in-an-era-of-transnationalism.pdf? $v=1>$. Acesso em: 01.06.2014.

TOCQUEVILLE, Alexis de. A Democracia na América. Livro 1, Leis e Costumes. São Paulo: Livraria Martins Fontes, 2005.

WALDINGER, Roger. The Cross-Border Connection: Immigrants, Emigrants, and Their Homelands. Cambridge, Massachusetts: Harvard University Press, 2015. 